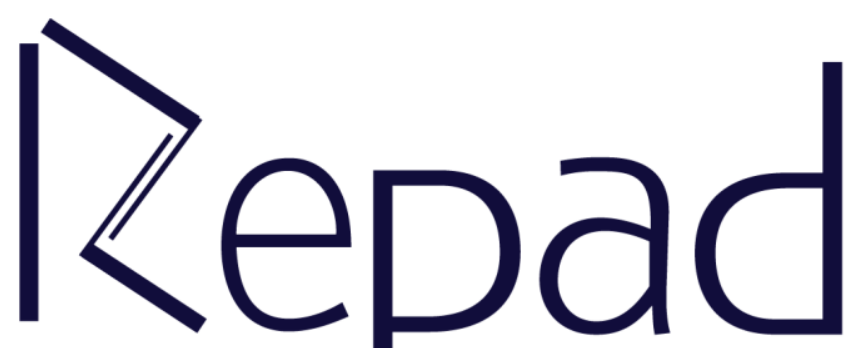

vol. 3, n. 3, Setembro-Dezembro/2019

Revista Estudos e

Pesquisas em Administração 


\title{
VITRINE DE INSATISFAÇÃO: Um olhar para o pós-vendas das relações comerciais de eletroeletrônicos em plataformas digitais
}

\author{
Lucas Adriano Dias Ramos \\ Universidade Federal de Mato Grosso, Cuiabá, Mato Grosso, Brasil \\ e-mail: lucasadrianodias@gmail.com \\ https://orcid.org/0000-0001-7879-3782 \\ Francisco Mirialdo Chaves Trigueiro \\ Universidade Federal de Mato Grosso, Cuiabá, Mato Grosso, Brasil \\ https://orcid.org/0000-0002-4704-2764
}

\begin{abstract}
Resumo
A evolução tecnológica trouxe muitas mudanças ao cotidiano da sociedade, principalmente em relação ao comércio. Um comportamento mais exigente do consumidor forçou as organizações a agir de forma mais proativa, tornando-as cada vez mais responsáveis pelo envolvimento do cliente. O objetivo geral deste artigo foi analisar os principais motivos de reclamações de consumidores na plataforma digital Reclame Aqui, referentes ao processo de compra de eletrônicos no período 2017-2018. O formulário de pesquisa escolhido foi o descritivo, com coleta de dados diretamente no portal ReclameAqui. As informações extraídas das reclamações determinaram as perspectivas de vendas no ambiente virtual e o mau funcionamento foi a principal reclamação, também ocorreu um grande número de reclamações não resolvidas e os clientes mostraram uma avaliação negativa da falta de proatividade das empresas de vendas no processo de solução de problemas.
\end{abstract}

Palavras-chave: E-commerce; Pós-venda; Plataformas digitais; Reclamações de clientes.

\section{DISSATISFACTION WINDOW: An aftersales look at electronic trade relations on digital platforms}

\begin{abstract}
Technological evolution has brought many changes to society's daily life, especially in relation to commerce. More demanding consumer behavior has forced organizations to act more proactively, making them increasingly responsible for customer engagement. The general objective of this paper was to analyze the main reasons for consumer complaints on the Reclame Aqui digital platform regarding the process of buying electronics during 2017-2018. The chosen research form was the descriptive with collection of data directly on the ReclameAqui portal. Information extracted from complaints determined the outlook for sales in the virtual environment, and malfunction was the main complaint, a large number of unresolved complaints also occurred, and customers showed a negative assessment of the lack of proactivity of the sales companies in the process of troubleshooting.
\end{abstract}

Keywords: E-commerce; Aftersales; Digital Platforms; Complaints.

Submetido: 29/07/2019

Aceito: 07/09/2019

Publicado: 31/12/2019 


\section{INTRODUÇÃO}

A evolução tecnológica trouxe muitas mudanças para o cotidiano da sociedade e isso impactou também o comércio. O comportamento mais exigente dos consumidores obrigou as organizações a agir de forma mais proativa, tornando-as cada vez mais responsáveis pela captação do cliente. Uma dessas mudanças foi a migração dos consumidores das lojas físicas para as lojas online, possivelmente pela percepção do diferencial de preço e variedade, esse fluxo levou para o mercado online os problemas comuns do comércio físico e acrescentou questões específicas dessa modalidade, como a logística.

Segundo a Confederação Nacional de dirigentes lojistas (2017), cerca de $43 \%$ dos consumidores estão comprando mais em plataformas digitais, sendo que $87 \%$ estão satisfeitos, embora $30 \%$ afirme que ainda tem certo receio quanto a não receber o prometido.

Em publicação realizada pelo portal Brasil Econômico (2016), 92\% dos compradores buscam por informações sobre as empresas antes de realizar alguma compra ou contratar serviços e uma das plataformas utilizadas para este fim é o Reclame Aqui, que funciona como um mural de denúncias feitas pelos clientes gerando um ranking do número de reclamações e indicadores importantes para a reputação das empresas.

Segundo Schiffman, Sherman e Cohn (2008), citados por Hor-Meyll, Barreto, Chauvel e Araujo (2012), investigar sites e comunidades virtuais por meio de observação não intrusiva possibilita que as empresas conheçam as demandas de seu público para definir novas estratégias e adequação de suas ofertas.

Para buscar resultados mais precisos foi necessário delimitar o objetivo da pesquisa a reclamações sobre eletroeletrônicos registradas no portal de janeiro de 2017 até 13 de dezembro de 2018.

Foi evidenciado através das análises que os motivos das reclamações são de origem dos processos internos das empresas sendo que já existem trabalhos que estão em busca de compreender esses percalços para colaborar no aperfeiçoamento das organizações (HOR-MEYLL et al., 2012).

A justificativa desta pesquisa caracteriza-se em dois pontos principais a) de forma organizacional e empírica, identificando os principais percalços ocorridos na venda, na melhoria da relação entre empresas e consumidores, b) de forma teórica e cientifica, sendo fonte e inspiração para futuras pesquisas e produção de conteúdo.

A questão escolhida para nortear esse estudo foi quais as principais reclamações ocorridas no processo de compra de eletroeletrônicos em plataformas digitais?

O objetivo geral deste trabalho é analisar os principais motivos das reclamações dos consumidores na plataforma digital Reclame Aqui na compra de eletroeletrônicos durante o ano de 2017 até 13 de dezembro de 2018.

Esse artigo está estruturado em cinco seções sendo a introdução, fundamentação teórica, procedimentos metodológicos, apresentação e discussão dos resultados e considerações finais.

\section{FUNDAMENTAÇÃO TEÓRICA}

Nesta seção é estruturada uma base teórica útil para a compreensão dos resultados e análises posteriores, tais como administração de marketing, administração de vendas, 
comércio eletrônico e marketing digital, plataformas digitais para reclamações de consumidores.

\subsection{Administração de Marketing}

Segundo a AMA (Associação Americana de Marketing, 2017) o "marketing é a atividade, conjunto de instituições e processos para criar, comunicar, entregar e trocar ofertas que tenham valor para clientes, parceiros e sociedades em geral".

Como indicado por Abraham Maslow as necessidades básicas do indivíduo estão ligadas a sobrevivência como água, comida, ar, entre outros. Quando a necessidade é específica por determinado produto pode-se identificá-la como desejo, e quando há o poder de compra nasce a demanda. A necessidade é inerente ao ser humano, e a percepção de que o marketing pode criá-la é considerada equivocada, sendo que o profissional de marketing apenas utiliza fatores sociais para criar um desejo (KOTLER; KELLER, 2013).

Já Cobra (2009, p. 40) define que a "essência do marketing é um estado da mente. $\mathrm{E}$, portanto, as decisões em marketing adotam o ponto de vista do consumidor. As decisões mercadológicas são dirigidas para atender necessidades e desejos dos consumidores". O autor explica que a teoria de marketing está longe de ser considerada uma ciência exata, no entanto guarda preciosas informações de áreas cientificas como estatística, antropologia, psicologia e outras, além das questões artísticas que envolvem o design de produtos, embalagens e criação de ações publicitarias.

De acordo com Kotler e Keller (2013), a atividade chave do marketing é a busca pela identificação e satisfação das necessidades do consumidor, sendo que este conceito pode ser resumido em suprir necessidades gerando lucro. $\mathrm{O}$ que pode ser uma análise generalista do trabalho dos profissionais de marketing sendo que a sua composição envolve uma variada gama de atividades e áreas entrelaçadas.

Rocha e Platt (2015) defendem que, na interação da empresa com ambientes internos e externos, faz-se necessária a utilização de ferramentas como os 4P's do marketing. Sendo que Kotler e Keller (2013) estruturam os 4P's como:

- Produto: que está relacionado as características, marca, variedade, oportunidade de utilização.

- Preço: as formas de bonificações e descontos, preços de tabela, e condições de pagamento.

- Promoção: que é a propaganda, força de vendas utilizada, comunicação ao público.

- Praça: os canais de distribuição, localização do ponto de venda, estoque e transporte.

Para definir as melhores estratégias mercadológicas Campomar (2006, p. 1) define que a pesquisa, na área de marketing, é utilizada para "obtenção de informações, sendo um sistema de informações estruturado para tomada de decisão de administradores e gestores de qualquer nível de execução tanto estratégico, gerencial ou tático".

Ainda sobre a pesquisa na área de marketing Kotler e Keller (2006) ressaltam a importância na escolha do tipo da fonte de dados, sendo que dados secundários são os preferíveis devido a sua disponibilidade imediata e não apresentarem custo, já os dados primários demandam investimentos para serem trabalhados. 
Com os dados obtidos na pesquisa será feita a categorização dos dados, segmentando o mercado através dos perfis identificados. A segmentação de mercado é utilizada como recurso estratégico, pois possibilita o foco do planejamento mercadológico de forma eficaz, podendo ela ser descrita em três níveis: a) identificação de grupos como similaridades e suas diferenças; b) seleção do segmento alvo; e c) mapeamento homogêneo e elaboração do mix de marketing (TAVARES; AFONSO; LOCATELLI, 2011).

Sendo que a segmentação pode ser demonstrada de formas diferentes, como a geográfica, demográfica, psicográfica, e a comportamental, sendo essas formas de estabelecer um padrão para determinado público. (KOTLER; KELLER, 2013).

A partir da segmentação de mercado é possível administrar informações pertinentes ao perfil do cliente. Kotler (2013, p. 164) define que "...o comportamento do consumidor estuda como as pessoas, grupos e organizações selecionam, compram, usam e descartam artigos, serviços, ideias ou experiências para satisfazer suas necessidades e seus desejos".

Todos esses processos conceituados são parte importantes para efetivação do objetivo final que é o caminho que conduz a geração da venda.

\subsection{Administração de Vendas}

Kotler e Armstrong (2003) definem vendas como a comunicação verbal direta criada para demonstrar como produtos, serviços e ideias de uma pessoa ou empresa servem às necessidades de clientes em potencial. Para manter uma gestão eficaz das vendas é necessário ter conhecimentos de marketing, de estratégia, capacidade de analisar o comportamento de cada cliente e suas necessidade (NEVES; CASTRO, 2005). Os autores ainda apresentam o processo de venda inspirado originalmente nos estudos de Dubinsky (1980 apud NEVES; CASTRO, 2005, p. 16 ), que por sua aplicabilidade pode ser replicada em uma grande variedade de cenários, incluindo o comércio eletrônico, que é formado pelas seguintes fases e estão listadas na Tabela 1.

Tabela 1. Processo de venda

\begin{tabular}{|c|c|}
\hline Prospecção & Descrição \\
\hline Pré-abordagem & Momento da coleta de dados, preparação da proposta. \\
\hline Abordagem & Primeiro contato cliente e vendedor \\
\hline Apresentação da venda & Demonstrar a proposta, lidar com objeções \\
\hline Fechamento e pós-venda & Finalização da venda e o feedback do cliente. \\
\hline
\end{tabular}

Segundo Cabral (2008), o processo da venda precisa ser planejado de forma antecipada para que a empresa obtenha sucesso, mas antes disso a empresa precisa vender a sua imagem através do atendimento qualificado ao cliente, objetivando obter lucro sobre a venda.

Para que as organizações obtenham um resultado positivo, precisam empenhar esforços na área de vendas com foco na satisfação do cliente e propiciar satisfação aos vendedores em fazer parte dos seus objetivos que juntamente com a gerência darão 
suporte para que sua equipe desenvolva um trabalho de forma mais eficiente. (CABRAL, 2008).

A relação entre vendedor e um cliente raramente termina quando uma venda é finalizada. O relacionamento se potencializa após a venda (pós-venda) e ajuda a determinar a escolha do cliente na próxima compra (LEVITT, 1994).

Após a descrição do processo de venda é necessário abranger outros importantes tópicos desse processo como o comércio eletrônico e o marketing digital. Pois a participação, ou não, das empresas no ambiente virtual pode ser determinante para a efetivação de uma estratégia bem consolidada. Nas plataformas de venda virtual existem diversas formas de interação como mídias sociais, canais de vídeo e lojas virtuais, sendo seu diferencial a gestão do marketing digital como aliado nas ações de venda e pós-venda.

\subsection{Comércio Eletrônico e Marketing Digital}

Quando transferimos o olhar do cenário de vendas presenciais e passamos a relação comercial online, alteram-se as regras de negociação, as formas de identificar e alcançar os clientes, modelos de negócio, perfis de empresas e vendedores.

Segundo Torres (2009, p.48),

A internet é composta por uma rede de servidores, que são computadores ligados a internet e que se comunicam. Os servidores hospedam os sites, que são os programas ou aplicativos que contêm tudo o que você vê quando acessa a internet utilizando seu navegador. Hospedar, ou hospedagem, nada mais é do que manter todo o software do site no computador do servidor.

Segundo Nakamura (2011), o processo de nascimento do comércio eletrônico deuse através do desenvolvimento da internet nas bases do exército americano, através da empresa Arpa, interligando os departamentos de pesquisa com objetivo de reduzir a vulnerabilidade das informações. No ano de 1970, diversas universidades tiveram acesso a essa rede de comunicação, mas foi somente em 1979 que o inventor inglês Michael Aldrich desenvolveu a compra online, um sistema que processava pedidos através de uma televisão de 26 polegadas, para um computador doméstico efetivados em transação feita por linha telefônica. Já nos anos 1980, as diversas formas de comercio eletrônico como cartão de crédito, caixas automáticos e bancos via telefone foram desenvolvidos e depois aceitos.

Em 1995, o eBay e a Amazon.com iniciaram o caminho de sucesso do comércio eletrônico, onde o consumidor poderia realizar a sua busca e em questão de instantes ter uma relação completa de todas as opções. Hoje em dia, com a internet desenvolvida, os sites de compras online expandiram grandemente, os produtos agora são solicitados e pagos nos mesmos ambientes virtuais e as entregas são realizadas por serviços postais ou serviços de entrega comercial (NAKAMURA, 2011).

Percebe-se a necessidade de incluir a internet no planejamento de marketing, criando ações integradas que permitam realizar mais com os recursos disponíveis. A internet se tornou um ambiente que afeta a empresa de diversas formas, seja na comunicação corporativa ou na propaganda de produtos e marcas. Ao contrário da mídia tradicional de massa, em que o controle é dos grupos empresariais, na internet o controle é do consumidor, que tem a possibilidade de falar sobre seus produtos e serviços, fazer a 
comparação da sua empresa com os demais concorrentes e buscar formas diferenciadas de relacionamento com a sua marca (MIRANDA, 2010).

Nas palavras do presidente do SPC Brasil, Roque Pellizaro Júnior:

\begin{abstract}
A internet trouxe ao consumidor a liberdade de comprar quando e onde quiser. Se antes as pessoas tinham de ir até as lojas e demais centros de consumo, agora são os varejistas quem precisam encontrar seus clientes, oferecendo plataformas amigáveis, ofertas convidativas e informações relevantes para reter por mais tempo a atenção de potenciais compradores" (SPC Brasil, 2017).
\end{abstract}

Quando se fala em utilizar a internet como uma ferramenta de marketing, envolvendo a comunicação, a publicidade, propaganda e todas as possíveis estratégias e conceitos presentes na teoria do marketing, estamos falando em marketing digital, publicidade online, marketing web, publicidade na internet ou quaisquer outras composições criativas. Definir uma estratégia e analisar os resultados para verificar sua validade foi o comportamento adotado no início da internet, no entanto a atitude acarretou na crise das empresas ponto.com (TORRES, 2009).

O mesmo autor defende que a internet é tão grande e dispersa que os investimentos isolados e sem coordenação resultam, na maior parte das vezes, em desperdício de recursos. É necessário compreender antecipadamente todo o cenário de marketing digital e depois planejar ações coordenadas de forma eficiente, que estejam atreladas umas às outras e que se realimentem, ou seja, que uma ação contribua para que a outra cresça e obtenha projeção.

O comércio eletrônico é uma ferramenta que vem crescendo exponencialmente no mundo, transformando-se em vantagens competitivas para as empresas e facilidade de compra para os clientes, sendo que muitos consumidores ainda têm certo receio quanto a comprar pela internet e alguns preferem o contato físico com o produto aliado a assistência de vendedores especializados na hora da compra (COELHO et al., 2013).

Quando ocorrem problemas com a compra os consumidores buscam defender-se apelando para órgãos de representação e também a publicação das reclamações sobre suas experiências com as empresas, buscando solução para seus problemas.

\title{
2.4 Plataformas Digitais para Reclamações do Consumidor e Pós-Vendas das Empresas
}

Após o estudo quanto a satisfação dos clientes com relação a compras realizadas em ambientes digitais, os autores Ceribeli e Merlo (2015) observaram que a avaliação dos clientes é dividida por etapas do processo de compra desde o atendimento, características, ambiente e pós-venda.

A satisfação é percebida como a comparação do nível de desempenho do produto ou serviço percebidos pelo consumidor como um padrão de avaliação (WESTBROOK; OLIVER, 1991). Kotler (1994) acrescenta que quando há satisfação aumenta a probabilidade de recompra do produto ou insatisfação do consumidor onde geralmente respondem de forma diferente como abandonando a negociação ou devolvendo o produto, tomando medidas públicas, como reclamar da empresa.

Nesses ambientes, as reclamações são expostas, dando oportunidade as empresas de prestar um bom atendimento e solucioná-las de forma rápida. É percebido que os compradores buscam os sites de reclamação antes de fechar um negócio, avaliando qual 
o comportamento da empresa com relação as reclamações e a reação dos consumidores as soluções apresentadas.

No que tange a ideia de utilizar ferramentas online para alavancar vendas é extremamente importante considerar esses sistemas que, se gerenciados de forma correta, podem funcionar como um excelente propulsor de divulgação de uma marca.

\section{PROCEDIMENTOS METODOLÓGICOS}

Gil (2002, p. 17) diz que a "pesquisa pode ser definida como um procedimento racional e sistemático, cujo objetivo é proporcionar respostas aos diversos problemas propostos".

Inicia-se uma pesquisa apenas se existir uma pergunta, uma dúvida ou questionamento para qual se requer a busca de respostas. Pesquisar, portanto, é buscar respostas para algo, ou alguma coisa (SILVEIRA; CÓRDOVA, 2009).

Para isso, faz-se necessária a utilização de uma forma de levantamento de dados como explica Minayo (2002, p. 16) que define a metodologia como "o caminho do pensamento e a pratica exercida na abordagem da realidade", por meio dela incluir concepções teóricas de abordagem, sendo um conjunto de técnicas que possibilitam a construção da realidade. E através desse meio chegar ao objetivo que é a resposta aos que questionamentos levantados por esse artigo, de quais os principais percalços ocorridos no processo de venda de eletroeletrônicos em plataformas digitais.

\subsection{Classificação da Pesquisa}

A pesquisa descritiva foi a forma escolhida para desenvolver esse trabalho, por buscar descrever as características de uma população especifica ou determinado evento, a partir disso estabelecer uma relação entre variáveis. Utilizando diversas técnicas padronizadas para coleta de dados como o questionário e observação sistemática (KAUARK et al., 2010).

O foco do trabalho foi fundamentado pela ótica quantitativa, sendo que Fonseca (2002) defende que a pesquisa quantitativa é estruturada de forma diferente e preza pelos resultados que podem ser quantificados.

E para estruturar de forma eficaz a pesquisa e atingir corretamente os objetivos pré-estabelecidos na relação inicialmente, foi utilizado o procedimento de pesquisa documental, que Gil (2002) a define como materiais que ainda não receberam um tratamento analítico, ou que ainda podem ser reelaborados de acordo com o objeto da pesquisa, considerando que os esses materiais são oriundos de arquivos públicos, instituições privadas, incluindo ainda documentos de caráter pessoal. Assim, é possível considerar esse o melhor método, uma vez que a principal fonte de dados foram sites de empresas privadas.

\subsection{Objeto de Estudo}

O objeto de estudo é o motivo impulsionador da questão ou problema a ser pesquisado, e que o propósito desse resultado seja de importância para o pesquisador e de interesse comum (KAUARK et al., 2010). 
Para essa pesquisa a fonte de dados será a plataforma de reclamações Reclame Aqui, que teve seu início no ano de 2001. Caracteriza-se como um portal onde o consumidor pode realizar uma reclamação que entra numa equação com índice de resposta, índice de solução e se o consumidor voltaria a fazer negócio com a empresa. Esses dados podem resultar na reputação através de emojis com diversas expressões que podem expressar satisfação, ou não, e os comentários feitos em cada perfil das empresas estão disponíveis para os clientes e consumidores.

\subsection{Coleta de Dados}

O processo de coleta de dados é o conjunto de operações por meio dos quais o modelo de análise é confrontado aos dados coletados. O espaço de coleta é delimitado ao campo que a pesquisa, por exemplo, um espaço geográfico ou social, ou também espaço de tempo, gênero, idade, profissão renda ou outros (SILVEIRA; CÓRDOVA, 2009).

Nessa pesquisa a forma de coleta foi o levantamento de dados relativos aos principais problemas apresentados pelos clientes no portal Reclame Aqui. Para isso, utilizou-se o procedimento da coleta de dados documental, utilizando-se de informações do site de reclamações. O período selecionado para análise das reclamações foi de 1 de janeiro de 2017 a 13 de dezembro de 2018. Na Tabela 2 a seguir foram especificadas as principais variáveis da pesquisa bem como a sua descrição de avaliação.

Tabela 2. Variáveis de Análise

\begin{tabular}{|c|c|}
\hline Variável & Descrição \\
\hline Data da reclamação & $\begin{array}{l}\text { Analisar os principais meses de ocorrências de reclamações e } \\
\text { problemas. }\end{array}$ \\
\hline Empresas & As principais empresas que receberam reclamações \\
\hline Produtos & Os principais produtos fonte de reclamação \\
\hline Efetivação & Forma de efetivação da venda, em loja física ou online \\
\hline Problema & Tipo de problema reclamado \\
\hline Resposta da empresa & Se a empresa respondeu ou não \\
\hline Tempo de resposta & Tempo que levou para o primeiro contato da empresa com o cliente \\
\hline Prazo solução & Prazo que a empresa levou para solucionar o problema \\
\hline Resolvido ou não & Se o problema foi efetivamente resolvido \\
\hline Voltaria a fazer negócios & Se o cliente voltaria ou não a fazer negócios com a empresa \\
\hline Avaliação de Atendimento & Nota que o cliente deu para a resolução ou não do problema \\
\hline
\end{tabular}

\subsection{Análise dos Dados}

Para compreender, analisar e interpretar um material quantitativo, faz-se necessária a penetração nos significados que os atores sociais compartilham em sua vivencia de sua realidade. Essa forma de pesquisa é considerada a parte quantificável, ou seja, a tradução das opiniões em números e informações para agrupá-las e analisá-las, para isso é necessário o uso de recursos e técnicas estatísticas como percentagem, média, moda e mediana (KAUARK et al., 2010). 


\section{APRESENTAÇÃO E DISCUSSÃO DOS RESULTADOS}

A partir da contextualização desenvolvida no referencial teórico e das reclamações postadas no portal Reclame Aqui, essa seção busca analisar a postura das empresas perante a reclamação do consumidor e qual tem sido o resultado do pós-venda realizado, além de apresentar os principais resultados com base nas variáveis de estudo.

\subsection{A Plataforma Reclame Aqui}

Segundo a pagina institucional do site, a ideia ocorreu depois que seu fundador Mauricio Vargas ter sido prejudicado por uma empresa aérea, e não encontrando uma forma efetiva de expor sua insatisfação para também alertar outros clientes sobre a falha da empresa, e assim decidiu criar a plataforma.

Atualmente a média de acessos diários é de 600 mil pessoas pesquisando reputações das empresas. O site é dividido em categorias de produtos, comparação de empresas e a visualização de rankings ao qual é possível acompanhar os índices de respostas, resoluções de problemas. Em pesquisa realizada pelo próprio portal percebeuse que os consumidores passam em média 3 minutos e 11 segundos nas páginas do portal, que $56 \%$ dos consumidores cadastrados são do gênero masculino e $44 \%$ são do gênero feminino. Atualmente o portal conta com 15.000 .000 de consumidores cadastrados e 120.000 empresas com perfis ativos no site.

\subsection{Reclamações dos Consumidores na Plataforma Reclame Aqui}

A partir dos dados apresentados na Tabela 3, sobre os principais motivos de reclamações, observa-se que no período 2017-2018, o problema que recebeu mais citações foi o defeito de funcionamento, com $70 \%$, seguido de atraso nas entregas $9 \%$ e produto quebrado $6 \%$.

Tabela 3. Principais reclamações

\begin{tabular}{l|c|c|c|c|c|c}
\hline \multicolumn{1}{c|}{ Motivos } & 2017 & $\%$ & 2018 & $\%$ & Total & $\%$ \\
\hline Defeito de funcionamento & 49 & $70 \%$ & 72 & $70 \%$ & 121 & $70 \%$ \\
Atraso entrega & 1 & $1 \%$ & 14 & $14 \%$ & 15 & $9 \%$ \\
Produto quebrado & 5 & $7 \%$ & 5 & $5 \%$ & 10 & $6 \%$ \\
\hline Entrega não realizada & 6 & $9 \%$ & 0 & $0 \%$ & 6 & $3 \%$ \\
Propaganda enganosa & 2 & $3 \%$ & 4 & $4 \%$ & 6 & $3 \%$ \\
Mal atendimento & 3 & $4 \%$ & 1 & $1 \%$ & 4 & $2 \%$ \\
Sem assistência & 0 & $0 \%$ & 4 & $4 \%$ & 4 & $2 \%$ \\
Produto errado & 3 & $4 \%$ & 0 & $0 \%$ & 3 & $2 \%$ \\
Outros & 1 & $1 \%$ & 3 & $3 \%$ & 1 & $2 \%$ \\
Total & 70 & $100 \%$ & 103 & $100 \%$ & 173 & $100 \%$ \\
\hline
\end{tabular}

Fonte: Levantamento a partir do Reclame Aqui (2019)

Já os demais representaram índices menores como a entrega não realizada e propaganda enganosa com 3\% cada. Como Levitt (1994) teoriza, uma relação comercial cliente $\mathrm{x}$ vendedor não termina após o fechamento da venda e o responsável por potencializar essa relação é o pós-venda. Esse mecanismo determinará a escolha do cliente na próxima compra, principalmente em produtos de tecnologia. No caso das reclamações de defeito de funcionamento, as ações de pós-venda poderiam reduzir essa 
quantidade de reclamações em plataformas virtuais que tem se tornado vitrines de insatisfações de clientes. O pós-venda das empresas visa acompanhar a satisfação do cliente, antecipando a possibilidade de o cliente passar por algum problema com o pedido solicitado.

A Tabela 4 apresenta a quantidade de empresas que responderam às reclamações expostas pelos clientes. Em 2017, do total de 70 reclamações, apenas $1 \%$ não foi respondida, em 2018, das 103 reclamações apenas 18,44\% não foram respondidas, no acumulado dos dois anos 13,07\% não foram respondidas. Observa-se um aumento de reclamações de $33 \%$ entre os dois anos.

Após essa análise, pode-se utilizar os argumentos de Miranda (2010) que defende a adoção do marketing digital no planejamento estratégico das empresas por compreender que a internet se tornou um ambiente que influencia na comunicação corporativa, bem como na propaganda de marcas e produtos. Assim como Torres (2009) acredita que a internet é muito grande e qualquer tipo de investimento precisa ser corretamente direcionado, elaborando por meio de informações precisas quais as formas mais eficientes que sirvam para realimentar o sistema interno de tomada de decisão. E não deixar de responder às reclamações é importante, mas o fundamental é não deixar a reclamação acontecer na internet, desenvolvendo ações de marketing que antecipem o registro de insatisfação nas plataformas virtuais.

Tabela 4. Resposta das empresas

\begin{tabular}{l|c|c|c|c|c|c}
\hline \multicolumn{7}{c}{ Resposta da Empresa } \\
\hline \multicolumn{1}{c|}{ Respondeu } & 2017 & $\%$ & 2018 & $\%$ & Total & $\%$ \\
Sim & 69 & $99 \%$ & 84 & $82 \%$ & 153 & $88,43 \%$ \\
Não & 1 & $1 \%$ & 19 & $18 \%$ & 20 & $11,57 \%$ \\
Total & 70 & $100 \%$ & 103 & $100 \%$ & 173 & $100 \%$ \\
\hline
\end{tabular}

Fonte: Levantamento a partir do Reclame Aqui (2019)

Com relação à resolução das reclamações, a Tabela 5 informa que em 2017 o total de casos resolvidos foi $56 \%$, e em 2018 ocorreu uma elevação das resoluções de reclamações para $62 \%$, no total do período, $60 \%$ dos casos foram resolvidos pelas empresas, enquanto $40 \%$ não haviam sido solucionados. Sendo que esses resultados são números significativos, diante da dimensão que a internet tem hoje em dia, impactando produtos, marcas e empresas.

Tabela 5. Indicadores de solução

\begin{tabular}{l|c|c|c|c|c|c}
\hline \multicolumn{7}{c}{ Indicadores de solução } \\
\hline \multicolumn{1}{c}{ Resolveu o problema } & 2017 & $\%$ & 2018 & $\%$ & Total & $\%$ \\
Sim & 39 & $56 \%$ & 64 & $62 \%$ & 103 & $60 \%$ \\
Não & 31 & $44 \%$ & 39 & $38 \%$ & 70 & $40 \%$ \\
Total: & 70 & $100 \%$ & 103 & $100 \%$ & 173 & $100 \%$ \\
\hline
\end{tabular}

Fonte: Levantamento a partir do Reclame Aqui (2019)

Assim, a importância de uma avaliação positiva ou negativa para uma empresa pode ser o ponto chave para um cliente decidir realizar a compra. Portais como o Reclame Aqui funcionam também uma ferramenta de pós-venda visto que se usado corretamente pode tornar um impulsionador da marca. Outro ponto relevante são os índices de reclamações que aparecem ranqueados, e a partir do atendimento realizado pela empresa 
o cliente determinará uma nota que ficará exposta para futuras pesquisas, transformando assim em mais um meio do consumidor se proteger contra empresas inaptas no mercado.

$O$ interesse da pesquisa esteve baseado também em saber qual a satisfação dos clientes em relação ao atendimento recebido a partir da reclamação feita, conforme informado na Tabela 6. Para avaliar o atendimento durante os dois anos foi utilizado o indicador cliente voltaria a fazer negócio, avaliado de acordo com as variáveis sim, não e não deu feedback.

Tabela 6. Decisão do Cliente

\begin{tabular}{l|c|c|c|c|c|c}
\hline Cliente voltaria a fazer negocio & 2017 & $\%$ & 2018 & $\%$ & Total & $\%$ \\
\hline Sim & 13 & $19 \%$ & 9 & $9 \%$ & 22 & $13 \%$ \\
Não & 14 & $20 \%$ & 7 & $7 \%$ & 21 & $12 \%$ \\
Cliente não deu Feedback & 43 & $61 \%$ & 87 & $84 \%$ & 130 & $75 \%$ \\
Total: & 70 & $100 \%$ & 103 & $100 \%$ & 173 & $100 \%$ \\
\hline
\end{tabular}

Fonte: Levantamento a partir do Reclame Aqui (2019)

Em 2017, 19\% afirmaram que voltariam a fazer negócios, 20\% que não voltariam, mas $61 \%$ não deram feedback. Em 2018, apenas $9 \%$ dos clientes afirmaram que voltariam a fazer negócios com empresa, $7 \%$ disseram que não voltariam e $84 \%$ não deram feedback com relação ao atendimento. Esse último devido ao seu elevado número se torna um fator importante de averiguação por parte das empresas principalmente por que essas informações poderiam ser úteis para novas estratégias e formas de lidar com futuros problemas.

Uma proposta interessante para a plataforma seria de não autorizar o fechamento do chamado até o cliente avaliar se voltaria a fazer negócios com a empresa ou não, para ter um controle maior sobre as informações.

No levantamento foi identificado quanto tempo as empresas demoravam para responder as reclamações dos clientes. Na Tabela 7 mostra que em 2017, ocorreu com grande recorrência situações onde os chamados demoravam mais de 384 horas para serem respondidos sendo que essa frequência representou 29\%, seguido por 24 horas 16\%, 48 horas $11 \%$ e 12 horas $9 \%$. A média de prazo das respostas foi de 142 horas, a moda ficou em 24 horas, e a mediana com 72 horas (ou seja, até 50\% dos casos foram respondido em até 72 horas).

No ano de 2018 ocorreu um aumento de reclamações, bem como de não resposta pelas empresas $20 \%$. Além disso, $11 \%$ das respostas tiveram prazo superior a 384 horas, $15 \%$ das empresas responderam em 24 horas e apenas $6 \%$ responderam em até 12 horas. Um fator crítico foi o crescimento de $20 \%$ das reclamações não respondidas. No que se refere às medidas estatísticas descritivas, tem-se a média igual a 181,67 horas, bem acima do que notou em 2017, a moda continuou 24 horas e a mediana ficou em 120 horas, também acima do que se observou em 2017. Avaliando os dois períodos, o prazo acima de 384 horas totalizou $18 \%$ das recorrências, seguido de 24 horas $15 \%$ e 12 horas $7 \%$. A média ficou em 181,64 horas, a moda em 24 horas e a mediana em 120 horas. Sendo que a elevada dispersão do desvio padrão e coeficiente de variação em relação à média, evidenciou que embora prevaleça a moda de 24 horas, existiram casos que levaram muito mais tempo para a empresa realizar o primeiro contato com o cliente.

Esses dados são importantes para compreender qual o grau de eficiência das empresas no quesito atendimento, como o próprio conceito determinado pela (AMA, 2013) de que o papel do profissional de marketing se detém na premissa de identificar 
oportunidades, compreender problemas e monitorar o desempenho do trabalho prestado. Embora a maior parte seja respondida em 24 horas, há uma dispersão muito grande desse indicador, e acredita-se que as empresas que se prestam a realizar um trabalho de pósvenda deveriam dedicar-se a responder de forma mais rápida e assertiva.

Tabela 7. Tempos de respostas

\begin{tabular}{|c|c|c|c|c|c|c|}
\hline & & & & & & \\
\hline Horas & 2017 & $\%$ & 2018 & $\%$ & Total & $\%$ \\
\hline 12 & 6 & $9 \%$ & 6 & $6 \%$ & 12 & $7 \%$ \\
\hline 24 & 11 & $16 \%$ & 15 & $15 \%$ & 26 & $15 \%$ \\
\hline 48 & 8 & $11 \%$ & 6 & $6 \%$ & 14 & $8 \%$ \\
\hline 72 & 4 & $6 \%$ & 9 & $9 \%$ & 13 & $8 \%$ \\
\hline 96 & 2 & $3 \%$ & 7 & $7 \%$ & 9 & $5 \%$ \\
\hline 120 & 2 & $3 \%$ & 11 & $11 \%$ & 13 & $8 \%$ \\
\hline 144 & 2 & $3 \%$ & 4 & $4 \%$ & 6 & $3 \%$ \\
\hline 168 & 0 & $0 \%$ & 4 & $4 \%$ & 4 & $2 \%$ \\
\hline 192 & 2 & $3 \%$ & 2 & $2 \%$ & 4 & $2 \%$ \\
\hline 216 & 1 & $1 \%$ & 0 & $0 \%$ & 1 & $1 \%$ \\
\hline 240 & 0 & $0 \%$ & 2 & $2 \%$ & 2 & $1 \%$ \\
\hline 264 & 1 & $1 \%$ & 0 & $0 \%$ & 1 & $1 \%$ \\
\hline 288 & 1 & $1 \%$ & 1 & $1 \%$ & 2 & $1 \%$ \\
\hline 312 & 3 & $4 \%$ & 1 & $1 \%$ & 4 & $2 \%$ \\
\hline 336 & 3 & $4 \%$ & 1 & $1 \%$ & 4 & $2 \%$ \\
\hline 384 & 3 & $4 \%$ & 2 & $2 \%$ & 5 & $3 \%$ \\
\hline Maior que 384 Horas & 20 & $29 \%$ & 11 & $11 \%$ & 31 & $18 \%$ \\
\hline Não respondeu & 1 & $1 \%$ & 21 & $20 \%$ & 22 & $13 \%$ \\
\hline Total & 70 & $100 \%$ & 103 & $100 \%$ & 173 & $100 \%$ \\
\hline Funções & & 2017 & 2018 & Total & & \\
\hline Média & & 142,26 & 210,37 & 181,67 & & \\
\hline Moda & & $24 \mathrm{~h}$ & $24 \mathrm{~h}$ & $24 \mathrm{~h}$ & & \\
\hline Desvio Padrão & & $213,38 \mathrm{~h}$ & $456,61 \mathrm{~h}$ & $248 \mathrm{~h}$ & & \\
\hline Coeficiente de variação & & $150 \%$ & $217 \%$ & $137 \%$ & & \\
\hline Mediana & & $72 \mathrm{~h}$ & $120 \mathrm{~h}$ & $120 \mathrm{~h}$ & & \\
\hline
\end{tabular}

Fonte: Levantamento a partir do Reclame Aqui (2019)

Os dados relativos aos prazos de solução das reclamações foram estruturados na Tabela 8. Em 2017, 29\% das reclamações foram solucionadas após 384 horas, 16\% em até 24 horas e $11 \%$ até 48 horas, sendo que apenas $9 \%$ foram resolvidos em até 12 horas. A média de resolução dos problemas ficou em 587,43 horas, a moda foi de 24 horas e a mediana foi de 456 horas. Em 2018, dos registros identificados 23\% ficaram acima de 384 horas, $20 \%$ não foram respondidas, apenas $8 \%$ foi resolvido em 24 horas e um ponto negativo foi que apenas $4 \%$ dos casos foram resolvidos em até 12 horas. Sua média ficou em 544,98 horas a moda ficou 24 horas e 120 horas e a mediana em 144 horas. Um outro indicador importante dentro desta análise é a demonstração do desvio padrão e o coeficiente de variação, pode ser percebido que o mesmo varia muito em relação à média, sendo que o coeficiente de variação ficou acima de $200 \%$, mesmo a moda sendo em 24 
horas na moda. Registra-se que os dados da Tabela 7 não têm relação com a solução de reclamações, e sim, o primeiro contato da empresa com o cliente.

A busca pelo aprimoramento esperado pelas empresas, de acordo com essa tabela, não foi alcançada, a análise entre os anos demonstrou uma queda na proatividade da empresa em buscar solucionar o problema de forma efetiva almejando a satisfação do cliente. $\mathrm{Na}$ análise geral, 25\% dos casos foram resolvidos com mais de 384 horas, 13\% não foram resolvidos e, $11 \%$ dos casos tiveram solução em até 24 horas e apenas $6 \%$ foram resolvidos em 12 horas.

Tabela 8. Tempos de solução

\begin{tabular}{l|c|c|c|c|c|c}
\hline \multicolumn{1}{c|}{ Horas } & 2017 & $\%$ & 2018 & $\%$ & Total & $\%$ \\
\hline 12 & 6 & $9 \%$ & 4 & $4 \%$ & 10 & $6 \%$ \\
24 & 11 & $16 \%$ & 8 & $8 \%$ & 19 & $11 \%$ \\
48 & 8 & $11 \%$ & 7 & $7 \%$ & 15 & $9 \%$ \\
72 & 4 & $6 \%$ & 7 & $7 \%$ & 11 & $6 \%$ \\
96 & 2 & $3 \%$ & 5 & $5 \%$ & 7 & $4 \%$ \\
120 & 2 & $3 \%$ & 8 & $8 \%$ & 10 & $6 \%$ \\
144 & 2 & $3 \%$ & 3 & $3 \%$ & 5 & $3 \%$ \\
168 & 0 & $0 \%$ & 4 & $4 \%$ & 4 & $2 \%$ \\
192 & 2 & $3 \%$ & 3 & $3 \%$ & 5 & $3 \%$ \\
216 & 1 & $1 \%$ & 1 & $1 \%$ & 2 & $1 \%$ \\
240 & 0 & $0 \%$ & 1 & $1 \%$ & 1 & $1 \%$ \\
264 & 1 & $1 \%$ & 1 & $1 \%$ & 2 & $1 \%$ \\
288 & 1 & $1 \%$ & 2 & $2 \%$ & 3 & $2 \%$ \\
312 & 3 & $4 \%$ & 1 & $1 \%$ & 4 & $2 \%$ \\
336 & 3 & $4 \%$ & 1 & $1 \%$ & 4 & $2 \%$ \\
384 & 3 & $4 \%$ & 2 & $2 \%$ & 5 & $3 \%$ \\
Maior que 384 Horas & 20 & $29 \%$ & 24 & $23 \%$ & 44 & $25 \%$ \\
Não respondeu & 1 & $1 \%$ & 21 & $20 \%$ & 22 & $13 \%$ \\
Total & 70 & $100 \%$ & 103 & $100 \%$ & 173 & $100 \%$ \\
\hline Função & 2017 & 2018 & Total & & \\
Média & 587,43 & 544,98 & 504,20 & & & \\
Moda & $24 \mathrm{~h}$ & $24 \mathrm{~h}$ e 120h & 24 & &
\end{tabular}

Fonte: Levantamento a partir do Reclame Aqui (2019)

Já com relação ao nível de satisfação dos clientes posterior ao atendimento, na Tabela 9 demonstra que apenas 3\% dos atendimentos tiveram a nota máxima, sendo a maioria dos clientes não avalia o atendimento da empresa $77 \%$. Essa conjuntura demonstra que os clientes são ágeis para abrir a reclamação, mas morosos em relação ao fechamento e avaliação. Ressalta-se que em muitos registros foi possível observar o contato feito pela empresa solicitando essa avaliação e reforçando a sua importância para o trabalho da mesma. Na comparação dos anos a nota 0 representou $17 \%$ das reclamações em 2017 e 2018 obteve uma forte redução para 5\%, o que pode ser um reflexo direto do posicionamento das marcas perante ao resultado do ano anterior.

A partir dos dados expostos anteriormente é possível encontrar concordância nas palavras de Rímoli e Melo (2018) que afirma que o impacto das reclamações online tornam-se uma ameaça para uma organização, tendo uma publicação negativa visível a 
milhares de pessoas considerando assim um comportamento irresponsável e não ético podendo prejudicar a sua reputação. Sendo que as mesmas servem como indicadores, que possam permitir uma tomada de decisão rápida antes do agravamento da situação. Percebeu-se também a necessidade de maiores esforços na gestão das reclamações através de um olhar mais atento e sensível as demandas dos clientes.

Tabela 9. Notas de Atendimento

\begin{tabular}{|c|c|c|c|c|c|c|}
\hline Notas & 2017 & $\%$ & 2018 & $\%$ & Total & $\%$ \\
\hline 0 & 12 & $17 \%$ & 5 & $5 \%$ & 17 & $10 \%$ \\
\hline 4 & 1 & $1 \%$ & 0 & $0 \%$ & 1 & $1 \%$ \\
\hline 5 & 1 & $1 \%$ & 0 & $0 \%$ & 1 & $1 \%$ \\
\hline 6 & 2 & $3 \%$ & 1 & $1 \%$ & 3 & $2 \%$ \\
\hline 7 & 3 & $4 \%$ & 1 & $1 \%$ & 4 & $2 \%$ \\
\hline 8 & 1 & $1 \%$ & 4 & $4 \%$ & 5 & $3 \%$ \\
\hline 9 & 3 & $4 \%$ & 1 & $1 \%$ & 4 & $2 \%$ \\
\hline 10 & 2 & $3 \%$ & 3 & $3 \%$ & 5 & $3 \%$ \\
\hline Cliente não avaliou & 45 & $64 \%$ & 88 & $85 \%$ & 133 & $77 \%$ \\
\hline Total: & 70 & $100 \%$ & 103 & $100 \%$ & 173 & $100 \%$ \\
\hline
\end{tabular}

Fonte: Levantamento a partir do Reclame Aqui (2019)

Apoiando-se nas declarações dos autores, é recomendável a utilização de um sistema de gestão das reclamações devendo envolver não somente o processo de tratamento de reclamações, mas sim incorporar uma interface que colabore com a experiência do cliente, transmitindo a sensação de atenção as necessidades demonstradas. Sendo essa ação o resultado será a reconquista do autor da reclamação e também de outros consumidores impactando na reputação da empresa.

\section{CONSIDERAÇÕES FINAIS}

Este trabalho teve como objetivo analisar os principais motivos das reclamações dos consumidores na plataforma Reclame Aqui nos processos de compra de eletroeletrônicos durante o período de $1^{\circ}$ de janeiro de 2017 até 13 de dezembro de 2018, e as estratégias das empresas para solucionar os problemas.

A partir dos dados levantados em 173 reclamações dos consumidores, foram extraídos dados importantes para o aperfeiçoamento das organizações que utilizam plataformas digitais para oferecer seus produtos.

A reclamação com mais representatividade foi o defeito de funcionamento, sendo isso resultado do pós-venda falho executado pelas empresas tendo por consequência a insatisfação do cliente e redução das expectativas quanto aos produtos.

Das reclamações feitas, as empresas tiveram um primeiro contato eficiente com o cliente, deixando apenas uma pequena quantidade de reclamações passarem. No entanto, o indicador de solução demonstrou uma situação prejudicial para as empresas, quase metade das reclamações não foram resolvidas demonstrando uma clara ineficiência em gerenciar os problemas até a solução, gerando assim um alto índice de reclamações não resolvidas.

Os clientes que receberam um bom atendimento decidiram por continuar negociando com a empresa, no entanto, um índice equivalente também indicou que 
mesmo a empresa resolvendo o problema não voltaria a fazer negócios provavelmente pela ineficiência em encontrar uma solução para a demanda do cliente, mas uma situação importante foi descoberta na análise, mais da metade dos clientes não avaliaram a empresa nesse quesito assim como na avaliação de notas, onde a nota com mais destaque foi a nota zero. A média de tempo para resposta foi cerca de 181 horas e solução ficou em 504 horas. Sendo esses resultados informações de grande importância para o aperfeiçoamento das organizações, orientando-as a uma mudança de comportamento.

A importância do trabalho foi poder compreender os avanços das empresas no que diz respeito ao atendimento aos clientes por meio do marketing digital e de serviços de pós-venda. As plataformas de reclamação se tornaram um importante meio de expor um problema e no processo de compra e agilizar sua solução. Para a academia o artigo em questão se tornará fonte para futuras pesquisas e comparações abordando.

Com relação às limitações do trabalho identifica-se a falta de acesso aos clientes para obter informações mais precisas quanto a experiência de compra e a burocracia do acesso a resposta da empresa quanto a eficácia da ferramenta na gestão comercial.

Desse modo, sugere-se para futuros estudos e pesquisas um levantamento de dados de períodos mais longos para entender como foi o comportamento das empresas em comparação ao avanço tecnológico, qual a visão das empresas para projetos futuros quanto a interação cliente x empresa, ampliação do escopo de produtos analisados, pesquisas por meio de survey com clientes e aprofundamento das estratégias de marketing no meio digital.

\section{REFERÊNCIAS}

ASSOCIAÇÃO AMERICANA DE MARKETING - Definition of Marketing,

2017. Disponível em: < https://www.ama.org/AboutAMA/Pages/Definition-ofMarketing.aspx> Acesso em 14 de Outubro de 2018.

BRASIL ECONÔMICO - O Sac não funciona? Conheça os 5 canais para registrar denúncias e reclamações. Disponível em <http://economia.ig.com.br/2016-05-17/o-sac-nao-funciona-conheca-5-canaispara-registrar-denuncias-e-reclamacoes.html > Acesso em 17 de Maio de 2018.

CABRAL, C. D. Eficácia na administração de vendas: importantes procedimentos envolvidos. Revista de Ciências Empresariais, p. 40, 2008.

CAMPOMAR, M. C. Pesquisa em marketing e seus problemas versus pesquisa de marketing. v. 4, p. 23, 2006.

CERIBELI, H. B.; MERLO, E. M. E-Satisfação Em Compras De Alto E Baixo Envolvimento. E-Satisfaction in Purchases of High and Low Involvement., v. 9, n. 4, p. 1-22, 2015.

COBRA, M. Administração de marketing no Brasil. $3^{\circ}$ Edição ed. Rio de Janeiro: Elsevier Editora Ltda, 2009.

COELHO, L.; OLIVEIRA, R.; ALMÉRI, T. Crescimento do e-commerce e os problemas que o acompanham. Revista de Administração do UNISAL. C, p. 63-85, 2013.

FONSECA, J. J. S. Metafísica do Belo e Tríade Cultural. p. 1-127, 2002.

Confederação Nacional de dirigentes lojistas (2017) - 89\% dos internautas 
fizeram compras online no ultimo ano aponta estudo do spc e cndl https://www.cndl.org.br/noticia/89-dos-internautas-fizeram-compras-online-noultimo-ano-aponta-estudo-do-spc-brasil-e-cndl - Acesso em 9 novembro de 2018.

GIL, A. C. Como eleaborar projetos de pesquisa. $4^{\circ}$ Edição ed. São Paulo: Editora Atlas S.A, 2002.

HOR-MEYLL, L. F. et al. Por que consumidores reclamam de compras online? BBR - Brazilian Business Review, v. 9, n. 4, p. 133 a 156, 2012.

KAUARK, F. da S.; MANHÃES, F. C.; MEDEIROS, C. H. Metodologia da Pesquisa: um guia prático. Via Litterarum, p. 88, 2010.

KOTLER, P. Analyzing consumer markets and buyer behaviorSão PauloPrentice Hall, , 1994.

KOTLER, P.; ARMSTRONG, G. Principios de Marketing. Rio de Janeiro Prentice-Hall, 2003.

KOTLER, P.; KELLER, K. Administração de Marketing. $14^{\circ}$ Edicao ed. São Paulo: Pearson Education do Brasil, 2013.

KOTLER, P.; KELLER, K. L. Administração de MarketingSão PauloPearson Education do Brasil, , 2006.

LEVITT, T. Após a venda ter sido realizada, in Mantendo clientes. São Paulo: Makron Books, 1994.

MINAYO, M. C. DE S. Pesquisa Social : teoria, método e criatividadeEditora VozesPetrópolisEditora Vozes, , 2002.

MIRANDA, G. A. D. E. Mídias sociais - O Marketing como forma de comunicação. p. 1-48, 2010.

NAKAMURA, A. M. Comércio Eletrônico Riscos Nas Compras Pela Internet. Monografia, p. 55, 2011.

NEVES, M. F.; CASTRO, L. T. Administração de Vendas - Planejamento, estratégia e gestão. São Paulo: Editora Atlas S.A, 2005.

RECLAME AQUI - Plataforma de reclamação online - Eletroeletronicos Disponivel em: <https://www.reclameaqui.com.br/categoria/eletroeletronicos/> Acesso em 9 de Fevereiro de 2019.

RÍMOLI, T. T.; MELO, D. DE C. A Voz dos Consumidores em Redes Sociais: Proposição de um Modelo Eficaz de Gestão de Reclamações às Empresas. Revista Brasileira de Marketing, v. 17, n. 01, p. 49-64, 2018.

ROCHA, R. A.; PLATT, A. A. Administração de Marketing. $3^{\circ}$ Edição ed. Santa Catarina: DEPTO. DE CIÊNCIAS DA ADMINISTRAÇÃO (CAD/CSE/UFSC), 2015.

SERVIÇO DE PROTEÇÃO AO CREDITO - Consumo online 2017, Disponivel em: $\quad$ http://www.spcbrasil.org.br/wpimprensa/wpcontent/uploads/2017/release_consumo_online_2017.pdf Acesso em: 18 de novembro de 2018 .

SILVEIRA, D. T.; CÓRDOVA, F. P. A pesquisa científica. $1^{\circ}$ Edição ed. Porto 
Alegre: Universidade Federal do Rio Grande do Sul Capa, 2009.

TAVARES, M. C.; AFONSO, T.; LOCATELLI, R. L. Segmentação de mercado, diferenciação de produtos e a perspectiva da antropologia do consumo. Revista Gestao \& Tecnologia, v. 11, n. 1, p. 106-122, 2011.

TORRES, C. A Biblia Do Marketing Digital. $1^{\circ}$ Edição ed. São Paulo: Ltcla, Novatec Editora, 2009.

WESTBROOK, R. A.; OLIVER, R. The Dimensionality of Consumption Emotion Pattems and Consumer Satisfaction. Journal of Consumer Research, v. 18, p. 84-91, 1991. 